\title{
A synopsis of surgical training in Sri Lanka: the present
}

\author{
Pramodh Chandrasinghe \\ Department of Surgery, Faculty of Medicine, University of Kelaniya, Sri Lanka
}

\begin{abstract}
Second of a three part series based on personal correspondence with Dr. Upali Banagala, Prof. Ranil Fernando and Dr. Ranjan Dias on their experience and memories of surgical training in Sri Lanka.
\end{abstract}

The establishment of the Post Graduate Institute [PGIM] of Sri Lanka in the early 1980s helped to streamline the postgraduate medical training in Sri Lanka. The specialty of surgery, like all other specialties, which lacked a formal local qualification, also started to shape up its own homegrown training programme. This article describes the changes that took place in surgical training following the establishment of the PGIM based on personal communications with past chairpersons of the board of study for surgery.

The previous requirement of the fellowship of the Royal College of Surgeons [FRCS] in England was replaced by the Master of Surgery [MS] offered by the University of Colombo as the prerequisite to practice as a specialist surgeon. However the title of FRCS to date remains a common post nominal amongst surgeons more as a symbol of prestige or recognition.

The inception of the PGIM as well as the establishment of the MS examination has not been a smooth journey. According to Dr. Upali Banagala the first batch of candidates eligible to sit for the part I examination was under pressure by the trade union to boycott it. Only two candidates had sat for the exam, following which they had had to face turmoil. However by 1980 the examination process was accepted by the fraternity and eight candidates including him self had been able to successfully face the second part I exam conducted by the PGIM.

Part I of the MS conducted by the PGIM became the selection test for young surgeons to embark on surgical training. The entry exam took shape from the Part I of the FRCS, which was more or less the same structure as today's exam. Candidates hoping to take up Ophthalmology and ENT surgery also had

Correspondence: Pramodh Chandrasinghe

E-mail: pramodh@kln.ac.lk

(iD) https://orcid.org/0000-0002-3485-961X

Received: 21-11-2021 Accepted: 21-11-2021

DOI: http://doi.org/10.4038/sljs.v39i3.8918 to sit for the common part I exam. Ophthalmology, which deviated from MS part I in 1993, has agreed for a common selection exam again after almost three decades.

The local training following Part I of the MS had been 3 years in the early 1980 s following which they had to sit for the part II examination. All candidates had to under go training in general surgery and the main specialties in the likes of neurosurgery, orthopaedics, urology, cardiothoracic and trauma surgery. The sub-specialty rotations were added to the training programme with time. During this transition period, those with FRCS qualification were exempted from some pats of the training but had to complete the MS part II examination along with a post MS training period prior to obtaining board certification. During the early days the foreign placement was allowed for three years with one being without pay. The RCS in England had operated an overseas directives training scheme, which provided training opportunities for local trainees through the PGIM during the 1980's. Later on the College of Surgeons had mediated several training slots under the Medical Training Initiative of the RCS. However most trainees adopted to finding jobs through the direct applications to National Health Services vacancies through personal recommendations.

Even during the post PGIM era the lack of a structured formal training programme was felt. The board of study had introduced in-service training assessment during the early 90's under Prof. Aluwihare's chairmanship. However neither the trainers nor trainees took this up formally till the latter part of the next decade [2000-2009]. In around the same time the surgical education and training sessions [SETS], a teaching session for registrars on Saturdays at the college of surgeons, started to take shape. National trauma management course [NTMC] and several other training courses organized by the specialty associations also took shape during this time.

The current title of Doctor of Medicine [MD] Surgery for the surgical postgraduate qualification was adopted in 2011. The circumstances behind this change runs back for about two decades. Dr. Banagala recalls how the University of Colombo offered him a black cloak for the postgraduate convocation since MS was a master's degree as opposed to the MD of the physician's, which was regarded a Doctoral degree. As a result 


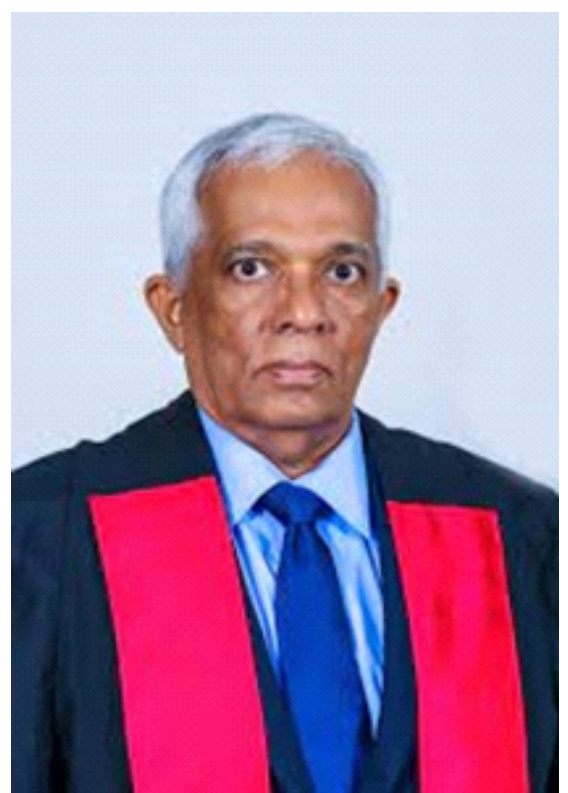

a]

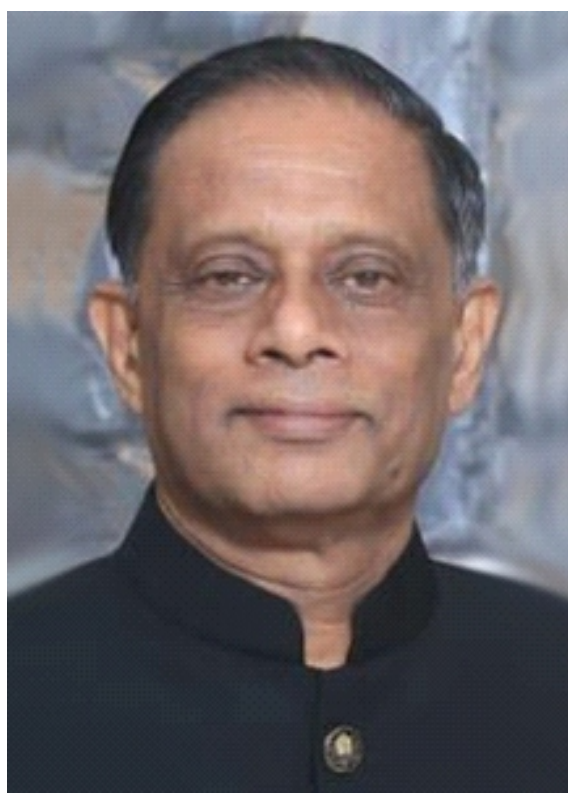

b]

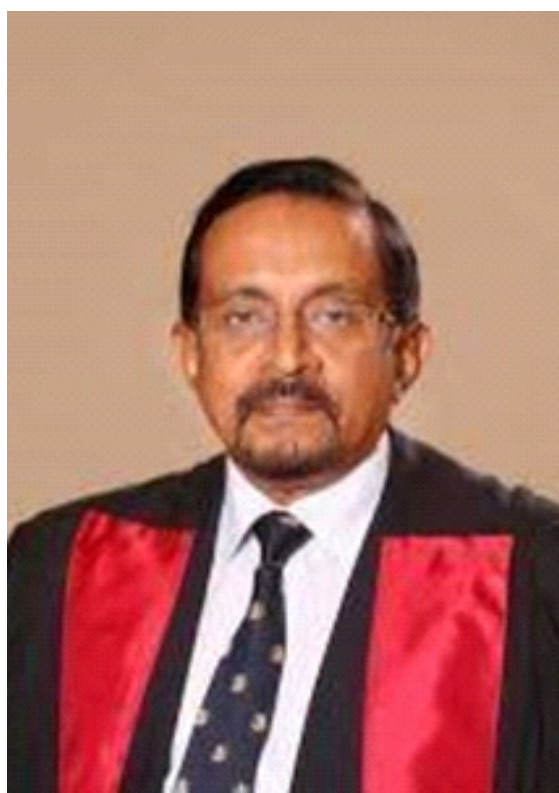

c]

a] Dr. Upali Banagala is a past secretary and a chairman of the board of study for surgery. Being an orthopaedic surgeon himself, he was instrumental in creating the speciality qualification of MD orthopaedics.

b] Prof Ranil Fernando was the chairman of the board of study for surgery from 2012 to 2015.

c] Dr. Ranjan Dias held the chairmanship of the board of study from 2015 till 2018.

the entire batch of surgical postgraduates in that year had boycotted the convocation. The current red cloak with a pink lining was subsequently established as a result of this incident. Dr. Banagala recalls how the MS awards continued to be awarded after honoring MD holders of all specialties. After much negotiation with the University of Colombo, the PGIM awarded the degree of MD surgery for the first time in 2011.

The specialty boards in surgery were established at the PGIM in 2009 with co-opted members from each board representing the board of study for surgery. The first and the only specialty board to branch out as a separate training programme and to have its own postgraduate qualification to date is the board of study in orthopaedics. Second part of the MD orthopaedics was held for the first time in 2011. The six month orthopaedics training for general surgical registrars have reduced to 4 months while the initial one year general surgery training for orthopaedics trainees have been pushed down to six months at present. Currently there are nine specialty boards functioning under the board of study in surgery viz: General Surgery, Gastrointestinal Surgery, Surgical Oncology, Urological Surgery, Paediatric Surgery, Plastic Surgery, Cardiothoracic Surgery, Vascular Surgery and Neuro Surgery [1].

General surgery also branched out into seven special interest areas [Upper gastrointestinal surgery, Hepato-pancreatobiliary surgery, Lower gastrointestinal surgery, Vascular surgery, Breast Surgery, Endocrine surgery and Trauma surgery] [2] during the same time, with trainees having to declare their special interest after completing MD part II examination. Two out of the three years of post MD training, currently has to be done in a specialized center of the declared interest. Professor Ranil Fernando who took over from Dr. Banagala as the chairman of the board of study points out that, the concerns regarding super saturation of general surgery speciality and the objective of giving an academic background with an enhanced training, were the principle driving forces of this branching out. In the backdrop of specialization it was mandatory for the trainers to submit a formal audit to the PGIM prior to being recognized as a training centre.

Decade starting from 2011 saw several paradigm shifts in the examination structure as well. Professor Fernando recalls the discussions held by the board of study opting for a complete overhaul of the MD part II examination structure. Also during this time the RITA was given more emphasis and it was made mandatory to return the assessment forms at regular intervals to be qualified for the exam. The trainees having to submit a minimum of one paper or three abstracts to be assessed by an examiner nominated by the board added prominence to the research component. The changing of the examination structure with the introduction of structured essays and MCQs for the MD part II exam was implemented in 2014. However the overall changes to the clinical and viva exams took shape in 2015 under Dr. Ranjan Dias. The clinical short and long cases were replaced by objectively structured clinical exams [OSCE] and observed history taking while the objectively structured vivas [OSVE] replaced the older viva-voce in principles, pathology and operative surgery. 
Introduction of external assessors [both local and foreign] for the exam was another pioneering initiative that took place post 2015 [3]. According to Dr. Dias this is the first time a local postgraduate exam had adopted a process to assess the exam and the performance of individual examiners. Currently the general Medical Council [GMC] and the Royal College of Physicians \& Surgeons of Glasgow have accepted the MD surgery qualification for license and membership without further assessment. The in-service assessment and the board certification structure also saw several changes. At the end of the post MD training it is mandatory for the trainees to undergo a desk assessment of the portfolio and a viva-voce examination by three senior examiners prior to board certification.

During the four decades since the inception of the PGIM, postgraduate surgical training in Sri Lanka has undergone significant structural changes for the better. Further changes to ensure a surgeon with sound skills; humane attitudes and a strong desire for progress will be a continued requirement. It will also be pertinent to formulate an assessment tool to assess whether the changes to the process are transferred to the 'end product' in the form of a continuous appraisal throughout a surgeon's career. Although the assessment of learning outcomes of the training programme is beyond the scope of this article, the third part of this series will shed light in to what each specialty envisages for the future of surgical training in Sri Lanka.
All authors disclose no conflict of interest. The study was conducted in accordance with the ethical standards of the relevant institutional or national ethics committee and the Helsinki Declaration of 1975, as revised in 2000 .

\section{References}

1. https://pgim.cmb.ac.lk/index.php/surgery/\#1558080508840$88 \mathrm{~d} 01 \mathrm{ba} 1-1 \mathrm{dab}$

2. https://pgim.cmb.ac.lk/index.php/surgery/

3. https://pgim.cmb.ac.lk/index.php/examiner-performanceevaluation-form/ 